\title{
THIO
}

\section{Performance measurement in corporate governance: Do mergers improve managerial performance in the post-merger period?*}

Ehsan H. Feroz, Professor, Corresponding author

School of Business and Economics, University of Minnesota Duluth Tel: 218/726-6988; fax: 218/726-8510; e-mail: efreroz@d.umn.edu

\author{
Sungsoo Kim \\ School of Business, Rutgers University \\ Camden, NJ 08012
}

\begin{abstract}
Ray Raab
School of Business and Economics, University of Minnesota Duluth Duluth, MN 55812-2496 USA
\end{abstract}

Please note: Readers wishing to copy or quote from this material must have prior permission from the authors. The algorithms used in this paper have provided a basis for Invention Disclosures with the University of Minnesota Patent Office.

*Earlier version of this paper benefitted from the helpful comments of the anonymous reviewers for American Accounting Association's Annual Meetings, and participant in the SBE Colloquium and Western Economic Association Meetings, especially Ilene Levin, Don Steinnes and John Griffith 


\title{
Performance measurement in corporate governance: Do mergers improve managerial performance in the post-merger period?
}

\begin{abstract}
Corporate finance studies of mergers and acquisitions have relied mostly on stock price reactions to evaluate the impact of these events. In this paper, we analyze the performance of a sample of merged firms over a ten year period using a managerially controlled efficiency measure, data envelopment analysis (DEA). Our individual firmlevel year-by-year analyses indicate that the managerial performance of the merged firms generally improved in the post-merger period as documented in the earlier corporate finance studies of mergers and acquisitions. However, there were also a significant number of cases where we could not observe improved managerial efficiency using this less aggregated approach. We conclude that DEA based disaggregated approaches are useful tools in the hands of corporate governance boards with an interest in yearly or even quarterly managerial performance at the individual firm level. DEA because of its individual firm level and yearly (or even quarterly) analysis avoids many of the problems of pooled cross-sectional regression analysis.
\end{abstract}

Keywords: Merger, Performance Measurement, DEA, Corporate Governance.

Data Availability: publicly available 


\section{Introduction}

Corporate finance studies of the evaluation of the efficiency generating potential of mergers and acquisitions have generally relied on stock price reactions to these events (Scherer 1988). Evidence from these studies are generally mixed in part because of the problems of segregating the effects of these events from other confounding events of interest to market participants. Healy, Palepu, and Ruback (1992) in an attempt to avoid the pitfalls of stock price studies rely on accounting cash flow based performance measures in order to determine the efficiency generating potential of mergers in the postmerger period. Kaplan, Mitchell and Wruck (1997) in a similar vein interviewed the managers involved in two different mergers in order to identify management practices that affect changes in post merger managerial performance and productivity. In this paper, we focus on managerial performance by examining directly and unobtrusively the managerially controlled accounting input-output measures in an attempt to compare the managerial performance of the individual firm in the pre- and post-merger period. In order to facilitate comparison with an earlier benchmark, we utilize the Healy et al. (1992) sample over a ten year period, approximately five years before and five years after the merger using a managerial performance efficiency analysis, i.e., data envelopment analysis (DEA). Our results based on individual firm level analyses over a ten year window indicate that the managerial performance of the firms generally improved in the post-merger period. However, in a significant number of cases (18\%) managerial performance efficiency did not improve. Our results have implications for managerial 
performance analysis by corporate governance boards, especially for mergers and acquisitions.

The motivation for this study was provided in part by the virtual lack of individual firm-level clinical performance efficiency analyses in the pre and post merger periods. In the Coasian tradition of the theory of the firm (1937) and related transaction cost analysis (Williamson 1975), surviving firms indicate that there must be some firm specific managerial efficiencies that are unlikely to be replicated by other firms in the same industry or else those firms would not have survived in the market in the first place. Often, conventional measures of efficiency operate at the aggregate level and fail to take into consideration firm specific managerial inputs that account for the efficient (or inefficient) outputs. Corporate governance decisions such as mergers and acquisitions often are attempts to discipline managerial behavior albeit initiated by market participants. Attempts to determine the impact of such governance control actions cannot solely rely on stock price reactions (for reasons elaborated in Scherer 1988). A more direct and unobtrusive way to gauge the impact of a governance control action such as merger is to look at the relationships between managerially controlled inputs and outputs over a period of time.

Earlier studies have demonstrated that DEA can complement the event study approach in order to capture the firm specific efficiency implications of a regulation (Smith 1990; Feroz, Raab and Haag 2001). DEA has also been applied to financial statement analysis and shown to provide additional information for market participants which is not readily available from individual ratio analysis (Athanassopoulos and Ballantine 2003; Feroz, Kim, and Raab 2003 and 2004). In this paper, we demonstrate 
that DEA, as a tool of efficiency analysis particularly focusing on the managerial performance of the firm at the individual firm level on a year by year basis, provides an excellent corporate governance tool for determining whether or not a governance control action such as merger increased or decreased the managerial efficiency of the firms in the post-merger period.

The rest of the paper is as follows: Section II articulates the case of DEA as a governance tool for managerial efficiency analysis. Section III describes the data and the methodology. Section IV reports the empirical results; Section V concludes the paper with implications of DEA as a tool for corporate governance.

\section{Managerial efficiency: A data envelopment analysis approach}

Traditional economic analysis of efficiency and resource allocation has relied primarily on stochastic estimation procedures using regression models. DEA is an analytical tool for evaluating the relative efficiency of a set of firms that exhibit the same multiple inputs and outputs. As a linear programming implementation of Farrell's (1957) notion of technical efficiency, DEA constructs an efficient frontier composed of those firms that consume as little input as possible while producing as much output as possible from the given level of input consumption. Those firms that comprise the efficient frontier are deemed efficient, while those firms not on the efficient frontier are deemed inefficient, or enveloped by the efficient firms. (See Appendix A for technical details.)

DEA can be applied to any revenue-producing entity by converting managerial performance indicators to their technical efficiency equivalents (Smith 1990). One such 
approach is to disaggregate Return on Equity (ROE) using the DuPont Method. ${ }^{1}$ ROE, measuring the relationship of net income to common equity, can be decomposed as follows:

$$
R O E=\left(\frac{N I}{S}\right)\left(\frac{S}{A}\right)\left(\frac{A}{E}\right)
$$

where:

profit margin $=$ net income $(\mathrm{NI}) /$ Sales $(\mathrm{S})$ asset utilization $=\operatorname{sales}(\mathrm{S}) /$ Total $\operatorname{Assets}(\mathrm{A})$ equity multiplier $=$ total assets(A) $/$ common equity(E).

This decomposition facilitates the examination of ROE in terms of a measure of profitability (profit margin), level of assets required to generate sales (asset utilization), and the financing of those assets (equity multiplier). Arguably, ROE encompasses sales, net income, total assets, and common equity.

These individual components define important dimensions of managerial efficiency of a firm. By focusing on increasing or decreasing these components, the managers can affect the ratio results. Profit margins measure the amount of each sales dollar remaining after covering all costs. The high profit margin means having as much net income as possible remaining after all costs are covered. If profit margins are to be improved, managers generally focus on minimizing costs. Greater improvement could be made if sales could also be increased at the same time that costs are decreased. The asset utilization (turnover) ratio measures the amount of assets required by managers to generate sales and can be improved by increasing sales and/or decreasing the level of total assets. The equity multiplier measures financial leverage. Profit margin times asset

\footnotetext{
${ }^{1}$ See Feroz, Raab and Haag (2001) for details.
} 
utilization equals the return on assets. Return on equity will be equal to return on assets for a firm that does not have any debt financing. The use of debt financing may allow the shareholders to realize a greater return on equity than return on assets as long as the debt level is not so high as to cause financial distress or borrowing above the return on assets.

A managerially efficient firm is one that produces the maximum output while consuming the minimum of inputs. Based on these ratios, the most efficient firm utilizes a minimum of sales, total assets, and common equity to produce a maximum of net income. The DuPont algorithm suggests that sales, total assets, and common equity can be minimized as inputs, and net income can be maximized as an output.

The additive DEA model algorithm (see Appendix A for technical details), unlike the other input or output oriented DEA models, simultaneously maximizes revenue and minimizes short and long term resources. The DEA approach to capturing net income is to simultaneously maximize revenue and minimize expenses. Because of the problem of explicit modeling net income ${ }^{2}$ and the fact that merger is more likely to affect the capital structure of the firm (depending on the method of financing mergers), our DEA model is as follows:

Max for Y1: Sales, and

Min for

$$
\begin{aligned}
& \mathrm{X} 1=\text { Long term debt, } \\
& \mathrm{X} 2=\text { Common equity, } \\
& \mathrm{X} 3=\text { Tax expense, } \\
& \mathrm{X} 4=\text { Interest expense, } \\
& \mathrm{X} 5=\text { Cost of goods sold, } \\
& \mathrm{X} 6=\sigma \text { return }
\end{aligned}
$$

s.t. GAAP constraints. ${ }^{3}$

\footnotetext{
${ }^{2}$ Because DEA does not work conveniently with negative numbers, the approach of explicity modeling net income may not be appropriate.

${ }^{3}$ We believe that the managerial discretion involving timing of discretionary accruals (five or ten year past period) will smooth out the future efficiency effects of mergers.
} 
Model 2 inspired by earlier formulations of Jensen (1983) and Smith (1990) maximizes sales and minimizes cost of goods sold, equity, debt, interest expense, tax expense and risk subject to discretionary and nondiscretionary accruals permitted under the US Generally Accepted Accounting Principles (GAAP). The specific COMPUSTAT data items used to specify each of these components are as follows: Longterm debt (COMPUSTAT \#9), Common Equity (COMPUSTAT \#60), sales (COMPUSTAT \#12), Cost of Goods Sold (COMPUSTAT \#12-13) ${ }^{4}$, Interest Expense (COMPUSTAT \#15), Tax Expense (COMPUSTAT \#16). The $\sigma$ return , the proxy for risk, is standard deviation of the annual stock returns calculated using daily CRSP tape. Pre-merger $\sigma$ return is calculated as a value weighted portfolio of the two individual firms' acquirer and target. Post-merger $\sigma$ return is for the combined firm. We believe that this is an appropriate measure of risk because the managers have a stewardship role regarding the overall risk of the firm, even though the managers do not have as good control of unsystematic risk. Further, we have utilized a risk measure constructed independently of the inputs (for example, debt to equity) already impounded in the model.

Implicit in equation 2 is the assumption that in the post-merger period, managers of merged firms will maximize the shareholder value as it was the intended message of a governance control action such as merger in the first place (Mendelker 1974). One measure of the increase in shareholders' value is to look at changes in stock prices - an approach that is fraught with problems of attribution of managerial responsibility and

\footnotetext{
${ }^{4}$ Sales - EBIT (Earrings before Interest and Taxes).
} 
causality to specific events such as merger to specific changes in share price. Our DEA modeling approach that relies predominantly on managerially controlled accounting inputs, makes the assumption that managers have significant control in their choice of inputs and eventual outputs, however, other economy wide effects cannot be discounted. ${ }^{5}$ Hence any specific changes in accounting outputs are attributable to the choices of managerial inputs in the pre- and post-merger period. ${ }^{6}$ We use a sufficiently long window of ten years $(-5,0,+5)$ to detect the effects of changes in managerial inputs and outputs. In the next section, we provide the details of data and methodology used to test the empirical DEA model as specified in equation 2.

\section{Data sources and methodology}

The data for sample firms over twenty years ranging from 1974 to 1993 were drawn from the 1994 COMPUSTAT Annual Tape and Annual OTC Tape. The returns for $\sigma$ return were calculated from the 1994 daily CRSP Tape. A total of 45 pairs of firms' data are available from both tapes out of possible 50 pairs which were used in Healy, et al. 1992. In order to operationalize equation 2, negative numbers in financial data have been adjusted. Specifically negative tax expenses (tax refund receivable) were added to the revenue in a few cases. If a sample firm has a negative common equity as in a few cases, data were converted into missing observations due to the input constraints imposed by the DEA model. Number of years available for data analyses before and

\footnotetext{
${ }^{5}$ One way to address this issue is to examine efficiency changes using the DEA methodology for companies in similar industries that did not merge. However the mergers in our sample were across industries with a minor exception.

${ }^{6}$ We assumed that the pre and post merger environments were not fundamentally different and that the major changes in the environment were the major mergers. We do not claim, however, that the increased efficiency in the post regulatory period was entirely due to merger.
} 
after the merger varies across the pairs of merged firms because of the timing of the event, merger, and COMPUSTAT cutoff points. Because we have used yearly data, there is no inconsistency between the generic definition of a decision making unit (or DMU as any revenue generating organization at any particular point in time) and the specific definition of DMU (annual accounting data of a revenue generating organization) used in this paper. We have simply used year as a unit of analysis in order to provide specificity to the periodicity concept of revenue generating organization.

Our methodology is to compare the managerial performance in the pre-merger to the post-merger periods. Thus a ten year $(-5,0,+5)$ or whenever possible a maximum of twenty-year $(-10,0,+10)$ efficiency comparisons were made. The managerial efficiency impacts of the merger can be determined by comparing the combined efficiency of the acquired firm and the acquiring firm during the pre-merger period (i.e., the 7 . variables in equation 2 describing the acquired and acquiring firms are summed) with the merged firm during post-merger period. Our methodology compares the efficiency scores (or more precisely stability index values) of the acquiring and acquired firm during the premerger period, with the new firm in the post-merger period. This firm-level time series clinical approach allows us to address the issue as to whether the net effect of merger in the post-merger period was to increase or decrease the managerial performance of the merged entity on a year by year and firm by firm basis and not just at the aggregate level as in most earlier studies. ${ }^{7}$

\section{Empirical results}

\footnotetext{
${ }^{7}$ We assumed that the pre and post merger environments were not fundamentally different and that the major changes in the environment were the major mergers. We do not claim, however, that the increased efficiency in the post regulatory period was entirely due to merger.
} 
When using the DEA model to measure temporal managerial efficiency effects of a merger, the years in which the observations are made are treated as DMUs (decision making units). For a given year, the merged firm in a post-merger year, or the two-firms combined as one in a pre-merger year is treated as a DMU. The relative temporal managerial efficiency of that year is evaluated as a deviation from the efficiency frontier comprised of all of the most efficient years. In this application, a maximum of 20 years were examined that included a variable number of pre-merger and post-merger years, depending on the exact merger date. Of the 45 firms for which adequate data was available, 24 firms had the full 20 years of data, while 4 firms had as few as 12 years of adequate data. $^{8}$

Table 1 summarizes the results of our analysis. The stability index represents the DEA measure of revenue efficiency determined by minimizing the costs and capital constraints of the entity. Given a DMU's (year's) classification of efficient or inefficient, the stability index ( $\theta$ values) measures the extent of the minimum perturbations (i.e., a simultaneous proportional increase in revenues and decrease in resources) required to move an inefficient year to become efficient, or the minimum perturbation (i.e., a simultaneous proportional decrease in revenue and increase in resources) required to move an efficient year towards the altered frontier to become inefficient. A large positive index value indicates a robustly efficient year. An index value near zero (positive or negative) indicates a firm requires only a small perturbation to change its efficiency classification. Finally, a large, negative index value indicates a robustly inefficient year,

\footnotetext{
${ }^{8}$ A commonly accepted DEA convention required that the minimum number of DMUs be greater than three times the number of inputs plus outputs. By using 20 years of data when 21 were required (three time six inputsplus one putput), we adjusted the basic DEA additive model by relaxing the lambda constraint (footnote 1) which did not predetermine the six inputs to be efficient and therefore allowed much better discrimination between efficient and inefficient years.
} 
which would require a relatively large simultaneous perturbation of revenues and resources in order to move that firm towards the efficient frontier. By using the stability index values ( $\theta$ values), it is possible to rank the "robustness" of a particular year, especially for efficient years comprising the frontier.

In Table 1, note that the merger year (noted in parentheses) is centered at time $t$ in Panel A. For example, American Medical International acquired Lifemark in 1984, five pre-merger years are noted over which two of the $\theta$ s are negative, indicating these years are inefficient and lie below the frontier comprised of the other nine efficient years. ${ }^{9}$ The pre-merger mean became 0.039 . The five post-merger years yielded a mean $\theta$ value of 0.086 . The difference between pre- and post-merger years yielded a -0.047 , indicating that on the average the post-merger years evidenced enhanced efficiency. Table 1, panel C provides the same analysis using a maximum of twenty year window $(-10,0,+10)$ whenever complete data is available for the sample. Of the 45 mergers analyzed here, 37 had zero or negative differences indicating that the combined firm has similar or improved managerial efficiency in the post-merger years. Eight differences were positive, indicating that the managers in post-merger years were less efficient than the pre-merger years. ${ }^{10}$

A further investigation of these eight firms with positive differences indicate that most of these firms had a "low overlap" in terms of structural compatibilities eventually leading to an unsuccessful merger experience. The performance of the Avon Products

\footnotetext{
${ }^{9}$ Our DEA frontier was established over a 20 year period but panel B examines only the stability indexes for five pre-merger years and five post-merger years in order to make our results comparable to Healey et al. (1992). Our results do not significantly change even when we use a 20 year window $(-10,0,+10)$ as evidenced in panel $c$, table 1 . Also, the ten year window $(-5,0,+5)$ used for the measurement of pre- and post-merger efficiency that minimizes exogenous factors beyond the control of managers.

10 The eight firms with positive differences are as follows: Anheuser-Busch, Avon, Coca-Cola, Litton, LTV, McGraw-Edison, RJR Reynolds, and Williams. If we use a twenty year window, only seven firms fall in this category: Avon, Brown-Forman, Coca-Cola, Litton, LTV, McGraw-Edison, and Williams.
} 
and Mallinckrodt during the six-year period after merger is an example of the performance of many of these mergers that eventually ended in divestitures. Avon's profit margin decreased noticeably in the period immediately following merger and it did not increase until after the sale of Mallinckrodt in 1986. As the New York Times Dec. 9, 1995, Vol. 145 (p. 50) summed up:

Avon acquired Mallinckrodt in 1982 as a part of a diversification strategy. In recent years, Avon has sold non-core business to focus on its direct selling cosmetics and apparel business ... Avon ultimately sold Mallinckrodt to the International Minerals and Chemicals Corporation. (p. 50)

Similarly Coca Cola's acquisition of Columbia Pictures was viewed with considerable caution and skepticism by analysts. Eric Morgenthals reported in the Wall Street Journal Jan. 20, 1983:

Coca Cola Co. announced its plans to go Hollywood one year ago with the acquisition of Columbia Pictures Industries, Inc. The transaction, completed last June for about $\$ 751.6$ million in cash and stock, initially evoked skepticism on Wall Street where many professionals thought the price was too high and the risky, free wheeling movie business a bad 'fit' for the predictable, conservative soft drink company.

The McGraw-Edison merger was similarly marred by prediction of mismatch as indicated in the Wall Street Journal July 25, 1979 (p.3) prognosis: 
.... Over the past 50 years the company has acquired more than 40 companies, most of them relatively small when they were acquired. During this time, the company became loosely organized and its earnings and growth records were lackluster.

Williams Company ratings was downgraded by Standard and Poor reflecting the financing needs of the company for its acquisition of Northwest Energy as documented by the Wall Street Journal, Nov. 3, 1983 (p.51).

Standard \& Poor's dropped the rating on Williams Cos. Debentures to double-Bminus from double-B-plus, reflecting financing needs for the company's recent acquisition of Northwest Energy Co.

Standard \& Poor's also downgraded ratings on debentures of Northwest Pipeline Corp., a subsidiary of Northwest Energy, to double-B from triple-B. The rating on Northwest Pipelines' preferred was reduced to double-B-minus from triple-Bminus. Rating on debentures and preferred of another Northwest Energy unit Northwest Central Pipeline Corp., were dropped to double-B-plus from single-A.

Northwest Energy's single-B rating on its preferred was withdrawn because the issue has been called for redemption. The four companies were removed after the changes from Standard \& Poor's CreditWatch list of concerns whose securities are liable for ratings revisions. 
LTV's proposed merger with Republic Steel was similarly marred by predictions of import curbs which might eventually hurt the merger:

Import curbs might hurt steel mergers: an important selling point for LTV Corp.'s pending bid to acquire Republic Steel Corp. Is the claim that existing threats of imports would prevent the merger from inducing competition and thereby driving up domestic steel prices: but this "world market" argument is undermined by the industry's push to limit imports. (Wall Street Journal, Jan. 4, 1984 (p.27)

U.S. Steel's merger with Marathon Oil was also not an uneventful one as reflected in the following Wall Street Journal, Jan. 7, 1982 (p.3) excerpt:

Failing a Supreme Court-ordered delay being sought by Mobil, U.S. Steel will be free at midnight to pocket half of Marathon's stock, 30 million shares, under its heavily oversubscribed $\$ 125$-a-share cash offer. The steelmaker proposes to acquire the rest of the Marathon shares in a yet unscheduled second-step merger by exchanging $\$ 100$ of $12.5 \%, 12$-year U.S. Steel notes for each share.

But what would those notes be worth a month or more hence? Given current bond market conditions, "only about 80 cents on the dollar," estimates Daniel Evans, E. F. Hutton \& Co., corporate bond analyst. If Mr. Evans and the many Wall Street bond merchants who agree with him are right, Marathon's stock, which fell 3 to $79 \frac{1}{2}$ yesterday, still is a bit overpriced, considered the wait. 
Another nettling problem: a spokesman for Bankers Trust, U.S. Steel's payment agent under the tender offer, says checks won't be ready for Marathon shareholders until next Monday morning, even though the offer expires tonight. He blames an anticipated heavy mechanical processing workload.

These comments provide corroborating evidence to the empirical DEA profiles provided in Table 1. Tables 2 and 3 summarize the proportion of positive $\theta \mathrm{s}$ by the years before and after the merger year, the higher proportion indicating more robustly efficient years. A pattern appears wherein the highest proportion of efficient years ( $80-100 \%$ positive $\theta \mathrm{s})$, occur in the ninth and tenth years prior and also the fourth to the fourteenth year after the merger year (80-100\% positive $\theta$ s for six out of the eleven $\theta$ s). As Table 3 indicates, the pattern around the merger year is particularly interesting as robust efficiency drops to $62 \%$ positive $\theta$ s four years prior to the merger, and rises subsequently up to a maximum of $84 \%$ positive $\theta$ s up to the merger year, and drops precipitously to the smallest percentage of positive $\theta$ s, or least robust efficiency in the year following the merger $(60 \%)$. The previous level of robust efficiency was not achieved until four years after the merger year ( $84 \%$ positive $\theta$ s in $t+4)$.

The pattern in Tables 2 and 3 can be compared to Healy et al. (1992) results. Raw returns in Healy et al.(1992) Table 3 are comparable to our $\theta$ values in that both are unadjusted for size and industry. Both measures show the decreased returns and efficiency right before the mergers. Raw returns in Healy et al. (1992) exhibit a sharp increase in the merger year as in the case with stability index values from our DEA model. Both Healy et al.(1992) and our results show strong raw returns and $\theta$ values 
right after merger. Our DEA model, which incorporates net income margin, cashflow margin, assets turnover, and equity multiplier (similar to various measures in Healy et al., 1992) produce one composite index by incorporating different aspects of managerial efficiency. These results confirm that overall mergers increase managerial efficiency, however, we found no evidence of expected increase in managerial efficiency in those cases $(18 \%)$ where there were low overlaps between the acquirer and target.

\section{Summary and conclusions}

In this paper, we have demonstrated the usefulness of the DEA-based clinical approach as a corporate governance tool for measuring managerial efficiency in the preand post-merger period. We analyzed the Healy et al. (1992) merger sample over a ten year period, approximately five years before and after merger by using a predominantly managerially controlled performance efficiency measure; i.e., DEA. Our results indicate that the managerial performance of the firms included in our sample generally improved in the post-merger period. However, there was a significant proportion of mergers $(18 \%)$ where there was no evidence of improved managerial efficiency in the post merger period. We believe that this is an important contribution to the managerial efficiency issues arising from governance decisions of mergers and acquisitions in that DEA by focusing on managerially controlled measures of inputs and outputs of individual firms provide firm specific and yearly measures of managerial performance using a common metric. DEA analysis, unlike aggregate performance measures, provides a much more individualized and less aggregated measures of managerial performance. In this sense, $\mathrm{DEA}$ is a finer tool at the discretion of corporate governance committees to determine the 
performance of managers on an individual firm by firm and year by year basis. DEA can be tailored by corporate governance consultants to a very short window (one or two years or quarters) or even a longer window, depending on the decision context and decision maker preferences. While decision makers need to be sensitive in interpreting DEA measures of efficiency, it is certainly an additional measure at the discretion of the governance board of directors, particularly the compensation committee, to determine whether the managers lived up to their promise, especially in the post-merger period. Finally, DEA because of its individual firm level and yearly (or even quarterly) analysis avoids many of the problems of traditional pooled cross sectional regression analysis, i.e., noncomparability of accounting and financing differences across mergers in a cross sectional pooled regression approach. We conclude, DEA based clinical approaches are useful tools in the hands of corporate governance boards with an interest in yearly or even quarterly managerial performance at the individual firm level. Similar approaches can also be applied to other corporate governance decisions such as management buyouts which take management efficiency as the primary goal, hostile takeovers where disciplinary actions are expected to lead to improved efficiency, or even apparently value increasing mergers that eventually lead to divestitures (Fluck and Lynn, 1999). 


\section{Appendix A.}

The original DEA model, known as the ratio or CCR model (Charnes, Cooper and Rhodes, 1978), has been improved by other DEA models, including the additive model (Charnes, Golany, Seiford and Stutz, 1985), the model of interest in this paper. In the additive DEA model, the observed input consumption and output production for a number of firms (or in our example, revenue generating organization at a particular point in time over a 20 year period or DMU) are measured. The measures of input consumption and output production for a given DMU or year are referred to as the DMU's component vector. The component vectors for all of the 20 DMUs are combined to form the empirical production possibility set, where empirical production possibility set $(\mathrm{PE})$ :

$$
P E=\left\{\left(Y^{T}, X^{T}\right)=\sum_{i=1}^{20} \mu_{i}\left(Y_{i}^{T}, X_{i}^{T}\right) ; \sum_{i=1}^{n} \mu_{i}=1, \mu_{i} \geq 0\right\}
$$

where $\mathrm{i}$ represents the general index of DMUs and $\left(Y_{j}^{T}, X_{j}^{T}\right)$ represent the output production and input consumption, respectively, for the $j$ th DMU.

The technical efficiency status (an efficient or inefficient year) for each DMU is determined by comparing its component vector to $\mathrm{PE}$. If no component vector in $\mathrm{PE}$, observed or hypothetical, can be found that strictly "dominates" the tested DMU, then the DMU is said to be technically efficient. Those DMUs for which a component vector can be found in PE that strictly dominates, are said to be technically inefficient. Figure 1 provides a graphical depiction of a set of DMUs for a single-input single-output example. From Figure 1, DMUs \#1, \#2, and \#3 would be technically efficient while DMUs \#4, \#5, 
$\# 6$, and \#7 would be technically inefficient. Segment $\overline{12}$ and $\overline{23}$ comprise the efficient frontier.

\section{Figure 1}

Mathematically, the test for technical efficiency of $\mathrm{DMUj}$ is determined by solving the following linear program:

$$
\begin{aligned}
\min \left(-e^{T} D_{y}^{-1} s^{+}-e^{T} D_{x}^{-1} s^{-}\right) \\
\text {s.t. } \quad=Y j \\
Y \lambda-s^{+} \\
X \lambda+s^{-}=X j \\
e^{T} \lambda s^{+}, s^{-} \geq 0
\end{aligned}
$$

where $\mathrm{Y}$ and $\mathrm{X}$ represent the matrices of the outputs and inputs, respectively; $\mathrm{s}^{+}$and $\mathrm{s}^{-}$ denote the shortfall in production and excess consumption slacks, respectively. The $\mathrm{e}^{\mathrm{T}}$ vector is the sum vector, guaranteeing a convex combination or scalar multiple (less than one) of the DMUs under scrutiny. ${ }^{11}$ As the additive model is not units invariant, we would note that $\mathrm{Y}$ and $\mathrm{X}$ are tranformed by the component averages in the objective

\footnotetext{
${ }^{11}$ The conventional additive model forces the $\lambda$ s to sum to unity $\left(\mathrm{e}^{\mathrm{T}} \lambda=1\right)$, guaranteeing that the efficient frontier is constructed of a convex combination of input and output levels. This constraint predetermines that a DMU with a unique minimum of any input must lie on the efficient frontier, regardless of how little output it may produce. By relaxing the lambda constraint as above $\left(\mathrm{e}^{\mathrm{T}} \lambda \leq 1\right)$, a particular DMU, even if it has a minimum of a given input, can be inefficient (see Haag, Jaska, and Semple, 1992). The conventional model is neither units invariant nor translation invariant.
} 
function to assure common results regardless of the units of measure chosen for each component. $^{12}$

This use of (4) serves only to categorize the observed DMUs as technically efficient or technically inefficient. ${ }^{13}$ In the proposed analysis, however, the execution of (4) does not yield a rank ordering of the DMUs from most robustly efficient to most robustly inefficient. To develop this rank ordering, one additional linear program must be executed for $\mathrm{DMUj}$, with the result yielding a $\infty$-norm measure of the minimum distance to a Pareto optimum point (efficient frontier).

Charnes, Haag, Jaska and Semple (1992) and Charnes, Rousseau and Semple (1996) developed a sensitivity analysis technique based on the $\infty$-norm measure of a vector that defines the necessary simultaneous perturbations to the component vector of a given DMU to cause it to move to a state of "virtual" efficiency." Virtual efficiency is defined as a point of the efficient frontier where any minuscule detrimental perturbation (increase in inputs and/or decreases in outputs) will cause an efficient DMU to become inefficient or any minuscule favorable perturbation (decrease in inputs and/or increase in outputs) will cause an inefficient DMU to become efficient.

For an efficient DMU, the $\infty$-norm measure (herein termed stability index) defines the largest "cell" in which all simultaneous perturbations to the input and output components will not cause a change of the efficiency status from technically efficient to

\footnotetext{
${ }^{12}$ Haag, Jaska, and Semple [1992] first introduced the notion of pre-scaling the data by component averages to create a units invariant model. See Haag and Jaska [1995] for a complete numberical analysis and explanation. See Lovell and Pastor [1995] for an alternative pre-scaling technique that must be used when the data contain zero $(0)$ and/or negative values.

${ }^{13}$ If input and output slacks are zero, then $\mathrm{DMU}_{\mathrm{j}}$ is deemed efficient. However, if either or both slacks are non-zero, then $\mathrm{DMU}_{\mathrm{j}}$ is deemed inefficient.
} 
technically inefficient. As such, the larger the stability index the more robustly efficient the DMU is said to be. Efficient DMUs with small stability indices will approach technically inefficiency with smaller detrimental perturbations than those efficient DMUs with larger stability indices. Mathematically, the stability index for efficient DMUj is determined by solving the following linear program:

$\min \theta$

$$
\begin{aligned}
& \text { s.t. } Y^{(E)} \lambda-s^{+}+\theta d_{0}=Y_{j} \\
& X^{(E)} \lambda+s^{-}-\theta d_{I}=X_{j} \\
& e^{T} \lambda \quad=1 \\
& \lambda, s^{+}, s^{-}, \theta \quad \geq 0
\end{aligned}
$$

where $\theta$ represents the stability index; $\mathrm{Y}^{(\mathrm{E})}$ and $\mathrm{X}^{(\mathrm{E})}$ represent the matrix of outputs and inputs, respectively, with the component vector for efficient DMUj omitted; $d_{0}^{T}$ and $d_{I}^{T}=$ $(1,1, \ldots, 1)$. Observe that $\theta$ simultaneously increases inputs and decreases outputs to arrive at an efficiency classification change. Figure 2 provides a graphical depiction of the $\infty$-norm measure (stability cell) for efficient DMU \#2.

Figure 2

For an inefficient DMU, the stability index defines the necessary minimum favorable perturbations (decreases in inputs and increases in outputs) that must be 
undertaken to cause the DMU to become virtually efficient. Therefore, the larger the stability index for an inefficient DMU the more robustly inefficient the DMU would be. That is, an inefficient DMU with a large stability index rests a greater distance from the efficient frontier than an inefficient DMU with a smaller stability index. Mathematically, the stability index for inefficient DMUj is determined by solving the following linear program:

$\max \theta$

$$
\begin{aligned}
\text { s.t. } Y \lambda-s^{+}-\theta d_{0} & =Y_{j} \\
X \lambda+s^{-} \theta d_{I} & =X_{j} \\
e^{T} \lambda \quad & =1 \\
\lambda, s^{+}, s^{-} \theta> & =0
\end{aligned}
$$

where all notations are defined in prior formulations. Observe that $\theta$ simultaneously decreases inputs and increases outputs to arrive at an efficiency classification change. Figure 3 provides a graphical depiction of the $\infty$-norm measure (stability cell) for inefficient DMU \#7. The stability index measures the sensitivity of the industry efficiency classification and is the measure utilized in this study to characterize the degree of firm specific efficiency or inefficiency of a particular pre- or post-merger year.

Figure 3 
Once the stability index is known for each DMU, the DMUs can be ranked from most robustly technically efficient to most robustly technically inefficient. To do so, the stability indices for inefficient DMUs are first negated. Then, the DMUs can be rank ordered from highest positive to lowest negative based on their stability index values. ${ }^{14}$

Table 1

Table 2

Table 3

Table 4

${ }^{14}$ See Adler, Friedman and Sinvany-Stern (2202) for a review of related DEA ranking techniques. 


\section{References}

Adler, N., Friedman, L. and Z. Sinvany-Stern. 2002. Review of ranking methods in the data envelopment analysis context. European Journal of Operations Research 140:249265.

Althanassopoulos, A. and J.A. Ballantine. 2003. Ratio and frontier analysis for assessing corporate performance: Evidence from the grocery industry in the UK. Journal of the Operational Research Society 464:427-440.

Charnes, A., Cooper, W. W., and E. Rhodes. 1978. Measuring the efficiency of decision making units. European Journal of Operations Research 2:429-444.

Charnes, A., W.W. Cooper, B. Golany, L. Seiford, and J. Stutz. 1985. Foundations of data envelopment analysis for Pareto-Koopmans efficient empirical production functions. Journal of Econometrics 30:91-107.

Charnes, A., S. Haag, P. Jaska, and J. Semple. 1992. Sensitivity of efficiency classifications in the additive model of data envelopment analysis. International Journal of Systems Science 23:789-798. 
Charnes, A., J. Rousseau, and J. Semple. 1996. Sensitivity and stability of efficiency classifications in data envelopment analysis. The Journal of Productivity Analysis 7: 518.

Coase, R. H., 1937. The nature of the firm. Economica N.S. 4:386-405.

Farrell, N.J. 1957. The measure of productive efficiency. The Journal of the Royal Statistical Society 120, 253-290.

Feroz, E. H., R. Raab, R. and S. Haag. 2001. An income efficiency model approach to the economic consequences of OSHA cotton dust regulation. Australian Journal of Management. 26 1:69-89.

Feroz, E. H., S. Kim, and R. Raab. 2003. Financial statement analysis: A data envelopment analysis approach. Journal of the Operational Research Society. 541: 4858.

Feroz, E. H., S. Kim, and R. Raab. 2004. Analytical procedures: A data envelopment analysis approach. Journal of Emerging Technologies in Accounting (forthcoming).

Fluck, Z. \& A.W. Lynn. 1999. Why do firms merge and then divest? A theory of financial synergy. Journal of Business, 72 3:319-346. 
Haag, S., P. Jaska, and J. Semple. 1992. Assessing the relative technical efficiency of agricultural production units in the Blackland Prairie, Texas. Applied Economics 24:559565.

Haag, S. and P. Jaska. 1995. Interpreting inefficiency ratings: An application of bank branch operating efficiencies. Managerial and Decision Economics, 16 1:7-14.

Healy, P., K. Palepu, and R. Ruback. 1992. Does corporate performance improve after mergers? Journal of Financial Economics 31:135-175.

Jensen, M. 1983. Organization theory and methodology. Accounting Review 58:319339.

Kaplan, S.N., M.L. Mitchell and K. H. Wruck 1997. A clinical exploration of value creation and destruction in acquisitions: Organizational designs, incentives and internal capital markets. Unpublished working paper. University of Chicago, NBER and Harvard University.

Lovell, C.A.K., and J. T. Pastor. 1995. Units invariant and translation invariant DEA models. Operations Research Letters 18:147-151.

Mandelker, G. 1974. Risk and return: The case of merging firms. Journal of Financial Economics 303-335. 
Scherer, F.M. 1988. Corporate takeovers: The efficiency arguments. Journal of

Economic Perspectives 2, 1:69-82.

Smith, P. 1990. Data envelopment analysis applied to financial statements. Omega 18:131-138.

Williamson, O. 1975. Markets and hierarchies-analysis and antitrust implications: A study in the economic of international organization. The Free Press, New York, 8-10. 


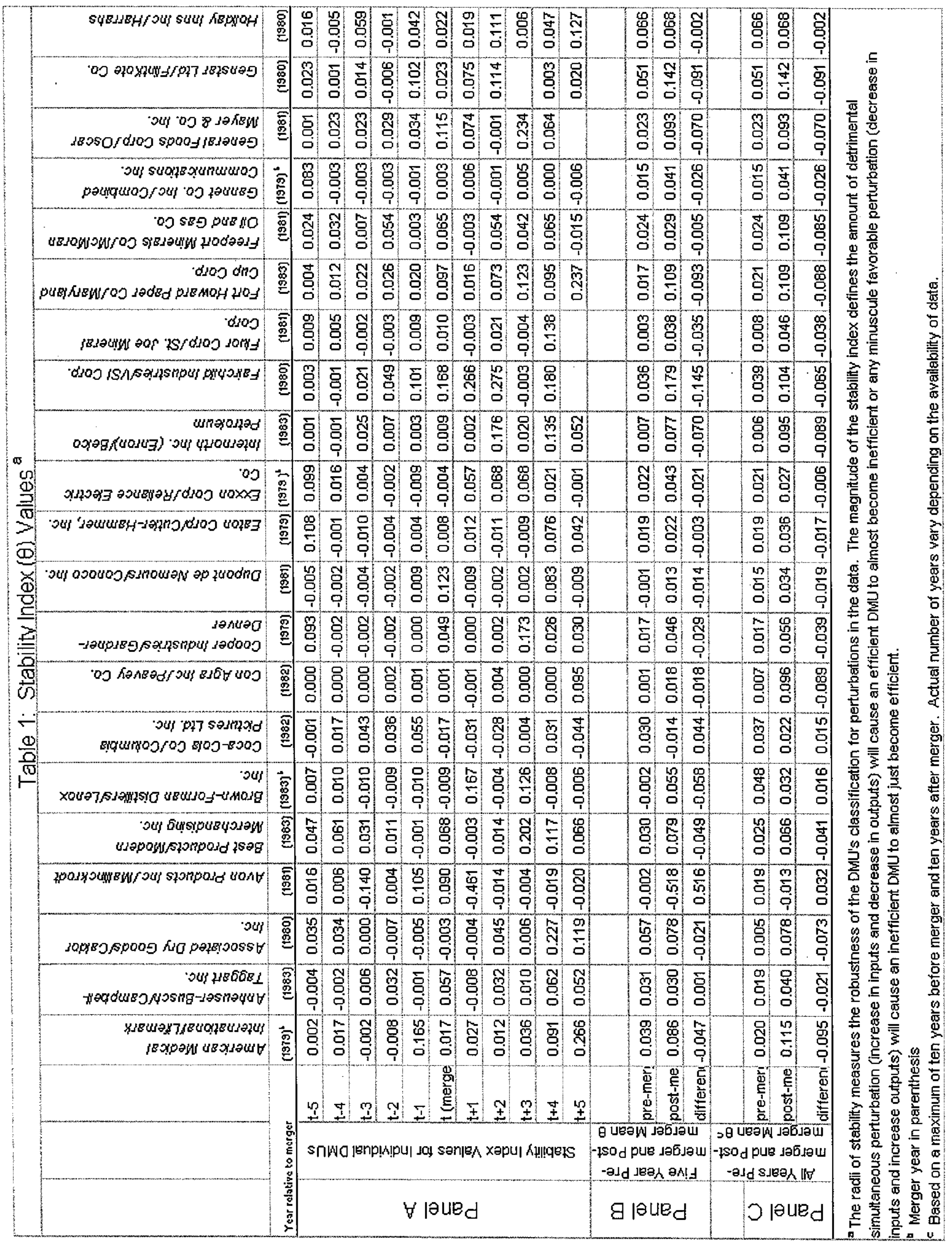




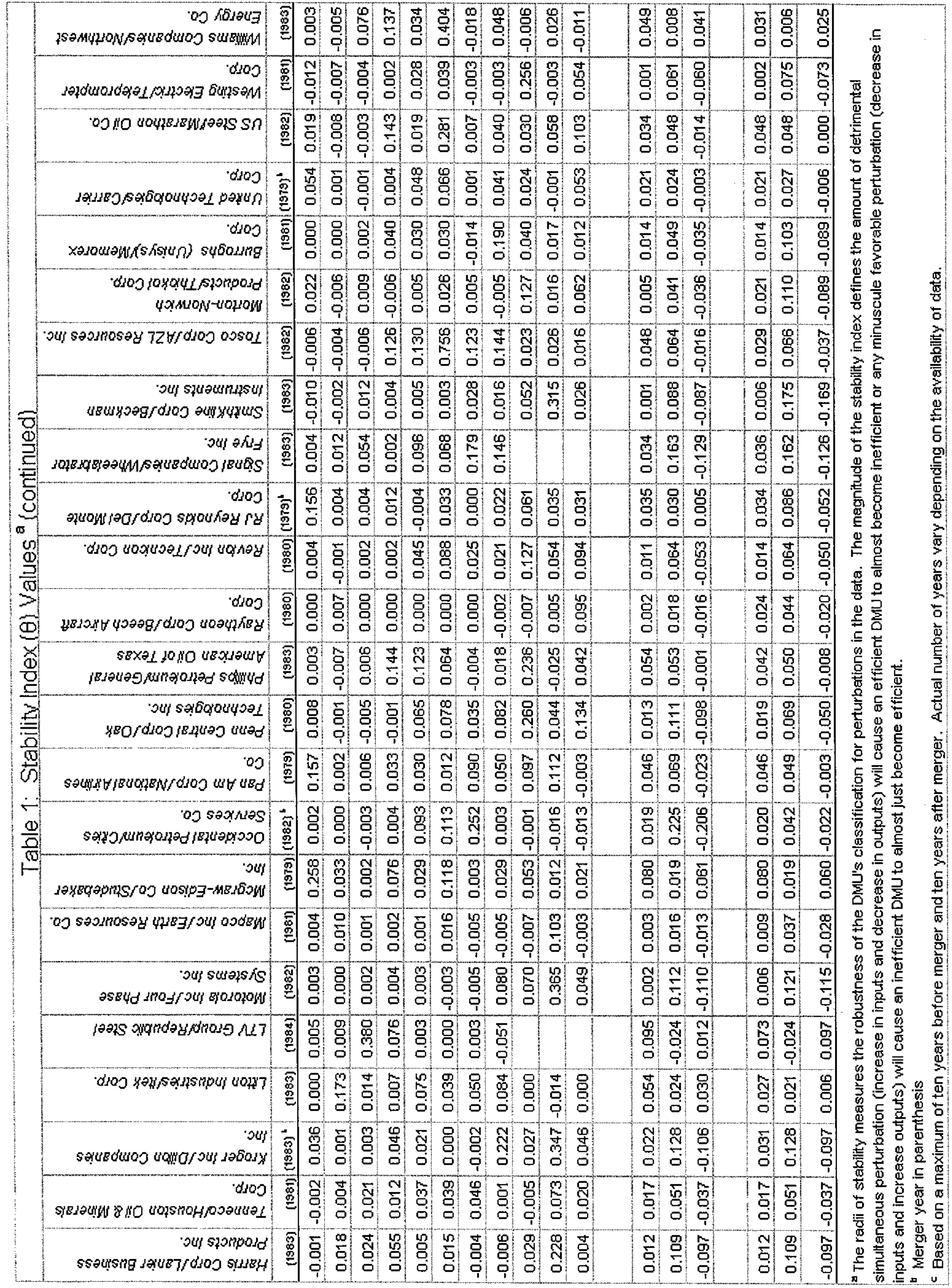


Table 2

Differences Between Before and After Mean $\theta$ Value

Panel A: Nonparametric Test Between Before and After Mean $\theta^{\mathrm{a}}$ Value $(-5,0,+5)$

$\begin{array}{ll}\mathrm{n}=45 & \text { mean } \theta \\ \text { Before } & 0.0259 \\ \text { After } & 0.0674\end{array}$

1) Wilcoxon Rank Sum Test

$Z=5.372 \quad P \geq|Z|=0.0001$

2) Median 2 sample test

$\mathrm{Z}=5.088 \quad \mathrm{P}>|\mathrm{Z}|=0.0001$

Panel B: Nonparametric Test Between Before and After Mean $\theta^{a}$ Value $(-10,0,+10)$

$\begin{array}{ll}\mathrm{n}=45 & \text { mean } \theta \\ \text { Before } & 0.0258 \\ \text { After } & 0.0506\end{array}$

1) Wilcoxon Rank Sum Test

$\mathrm{Z}=4.065 \quad \mathrm{P} \geq|\mathrm{Z}|=0.0001$

2) Median 2 sample test

$\mathrm{Z}=3.367 \quad \mathrm{P}>|\mathrm{Z}|=0.0001$

a The radii of stability measures the robustness of the DMU's classification for perturbations in the data. The magnitude of the stability index defines the amount of detrimental simultaneous perturbation (increase in inputs and decrease in outputs) will cause an efficient DMU to almost become inefficient or any minuscule favorable perturbation (decrease in inputs and increase outputs) will cause an inefficient DMU to almost just become efficient. 
Table 3 Summary of Positive $\theta^{a} \mathrm{~s}$

\section{Panel A: Summary of Positive $\theta$ 's by Year $(-5,0,+5)$}

\begin{tabular}{|c|c|c|c|}
\hline \multicolumn{2}{|c|}{ Relative to merger year } & $\begin{array}{c}\text { Number of Positive } \theta s \text { / } \\
\text { Total Number of Firms of That Year }\end{array}$ & Percentages (\%) \\
\hline $\mathrm{t}$ & -5 & $34 / 45$ & 76 \\
\hline $\mathrm{t}$ & -4 & $28 / 45$ & 62 \\
\hline $\mathrm{t}$ & -3 & $30 / 45$ & 67 \\
\hline $\mathbf{t}$ & -2 & $33 / 45$ & 73 \\
\hline $\mathbf{t}$ & -1 & $36 / 45$ & 80 \\
\hline & & $38 / 45$ & 84 \\
\hline $\mathbf{t}$ & +1 & $27 / 45$ & 60 \\
\hline $\mathbf{t}$ & +2 & $32 / 45$ & 71 \\
\hline $\mathbf{t}$ & +3 & $31 / 42$ & 69 \\
\hline $\mathbf{t}$ & +4 & $36 / 43$ & 84 \\
\hline $\mathbf{t}$ & +5 & $28 / 40$ & 70 \\
\hline
\end{tabular}

\section{Panel B: Summary of Positive $\theta$ 's by Year $(-10,0,+10)$}

\begin{tabular}{lrrr}
\hline $\mathbf{t}$ & -10 & $2 / 2$ & 100 \\
$\mathbf{t}$ & -9 & $10 / 12$ & 83 \\
& -8 & $17 / 22$ & 77 \\
& -7 & $19 / 31$ & 61 \\
& -6 & $24 / 37$ & 65 \\
& -5 & $34 / 45$ & 76 \\
& -4 & $28 / 45$ & 62 \\
& -3 & $30 / 45$ & 67 \\
$\mathbf{t}$ & -2 & $33 / 45$ & 73 \\
$\mathbf{t}$ (merger year) & -1 & $36 / 45$ & 80 \\
$\mathbf{t}$ & & $38 / 45$ & 84 \\
$\mathbf{t}$ & +1 & $27 / 45$ & 60 \\
& +2 & $32 / 45$ & 71 \\
& +3 & $31 / 42$ & 69 \\
& +4 & $36 / 43$ & 84 \\
& +5 & $28 / 40$ & 70 \\
& +6 & $23 / 34$ & 68 \\
& +6 & $21 / 30$ & 70 \\
& +7 & $24 / 30$ & 80 \\
& +8 & $22 / 29$ & 76 \\
& +9 & $23 / 29$ & 79 \\
& +10 & $19 / 21$ & 91 \\
& +11 & $12 / 14$ & 86 \\
\hline+12 & & 7 \\
\hline
\end{tabular}

a The radii of stability measures the robustness of the DMU's classification for perturbations in the data. The magnitude of the stability index defines the amount of detrimental simultaneous perturbation (increase in inputs and decrease in outputs) will cause an efficient DMU to almost become inefficient or any minuscule favorable perturbation (decrease in inputs and increase outputs) will cause an inefficient DMU to almost just become efficient. 
Figure 1

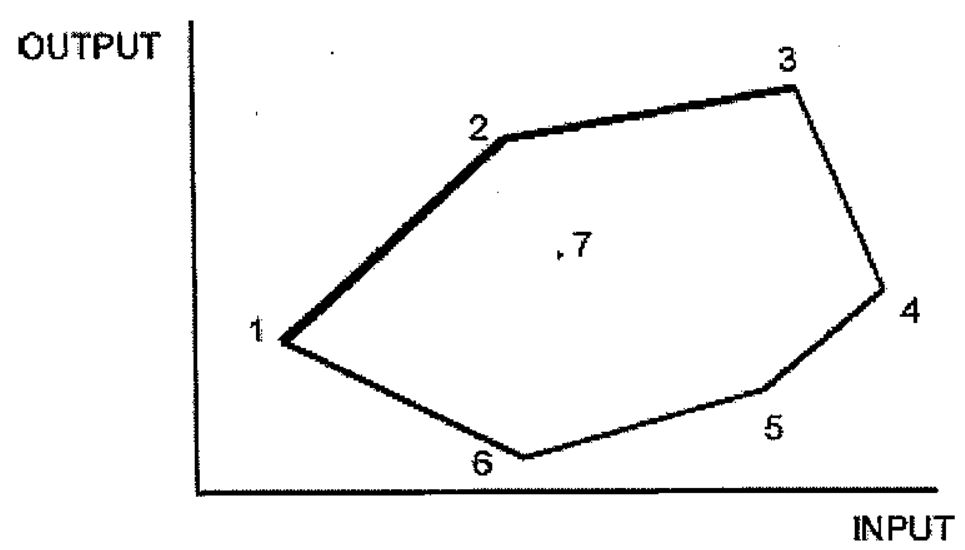


Figure 2

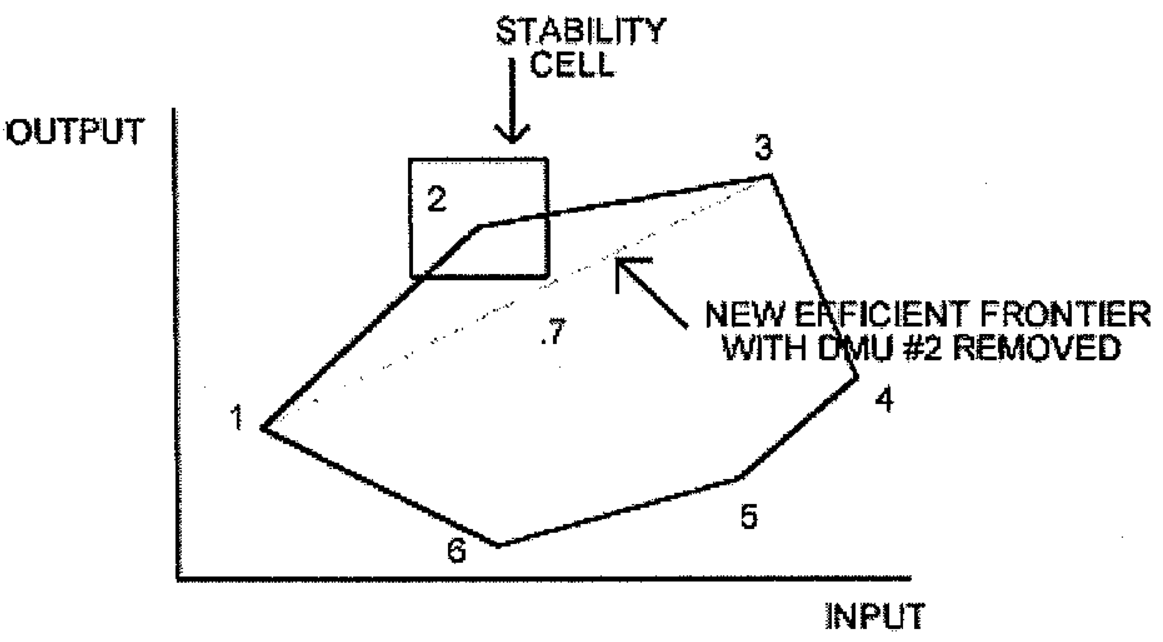


Figure 3

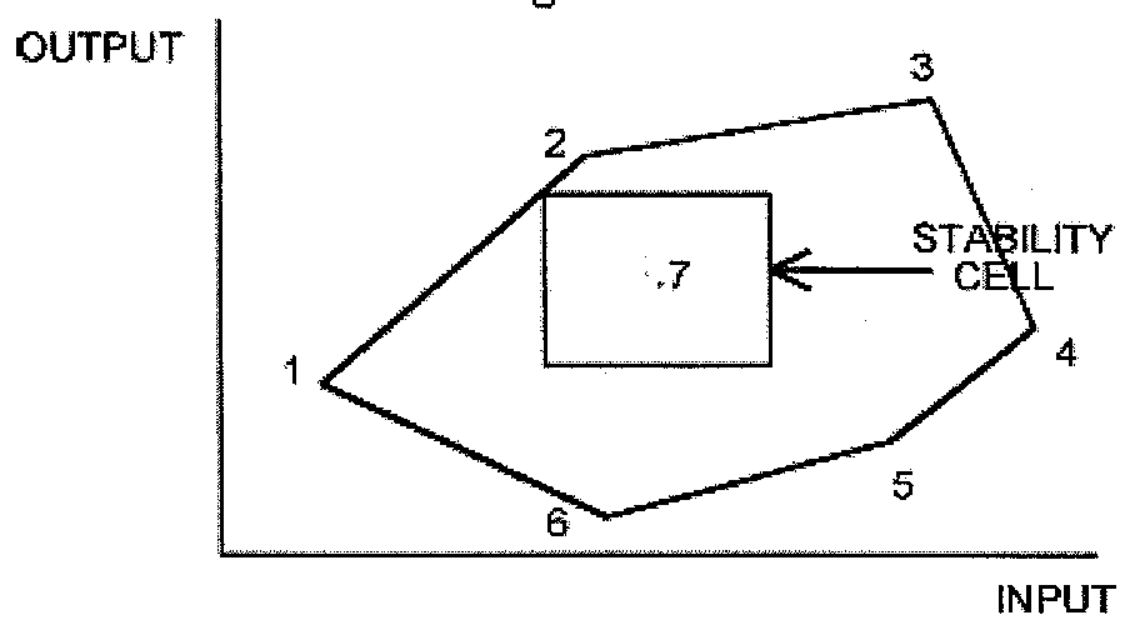

